\title{
Interactive White Boards' Added Value in Special Education
}

\author{
http://dx.doi.org/10.3991/ijoe.v10i6.4004 \\ Athanasios S. Drigas, and George Papanastasiou \\ NCSR DEMOKRITOS, Athens, Greece
}

\begin{abstract}
Interactive whiteboards indicate positive effects on students with special educational needs and promote a multi sensory style of learning. In this review paper we cope with the studies that explore the integration of IWBs in special education, in the last fourteen years (2000-2013). Research showed that interactive whiteboards are able to keep Special Education Needs students engaged in classroom facilities scaffolding their learning through technical and pedagogical interactivity. This technology has proven its value added to students with severe, complex, moderate learning disabilities, Autistic Spectrum Disorder, Attention Deficit Hyperactivity Disorder and on deaf, blind or physically impaired.
\end{abstract}

Index Terms-IWB, interactive, multimodal teaching, special education needs

\section{INTRODUCTION}

IWB offers a tangible and multimodal interface which fosters the learning capacities of Special Educational Needs' children, although their arrangement within the classroom setting in the teacher's 'territory', impacts negatively the children as users [1].

In the research presented by Bethany Stiefel, Interactive Whiteboard's implementation in self-contained Special Education settings is used for low academic instructions and limited uses, mainly for video, review games and teacher-led interactive websites. Thus, according to the survey, although the majority of the teachers surveyed feel that they received adequate training on using the IWB to foster instruction, one hundred percent of them think that professional development is needed to broaden their instructional uses with the IWBs and derive more in-depth use of them, to better meet the needs of the students [2].

In the future multimodal interfaces will engage human senses in a broader way through the synergy of blending technologies, online and onsite convergence, customized pedagogy, students as knowledge generators, not just consumers and immersive, gaming environment for teaching. Such interfaces support effectively struggling learners, children with special education needs stimulating different senses to focus attention (e.g. ADHD syndrome) [3].

The potential benefit of an IWB, engaging interactive lessons to students with special education needs, is significant. The combination of their verbal, auditory and tactile features encourages participation and motivates students to learn, employing multisensory methods that are much more interactive than in a flat, two-dimensional display of a blackboard [4].
According to SMART Technologies' white paper: Interactive Whiteboards and Learning, IWBs enable Visual learners of all ages to see their own writing and objects of their own creation, engage Kinesthetic or Tactile learners in classroom activities involving touch on an IWB, facilitate Deaf and hearing impaired learners with the presentation of visual material, enhance Visually impaired students with some visual ability to manipulate large objects and use large text on an IWB's big surface. Also IWBs foster attention of students with other special needs with learning challenges and behavioral issues [5].

Recent developments in assistive technology have created a high degree of interactivity among students, between students and curriculum and between students and teacher, in which the interactive whiteboards have played a decisive role to meet disabled students' diverse learning needs. The challenge to educators in thoroughly engaging disabled students to learning materials through IWBs' audio, visual and text features is to make sure they are not segregated by virtue of their being unable [6].

Children with developmental disabilities including physical disorders such as cerebral palsy and limited vision, as well as language and speech disorders not only could taste new teaching method but also enhance their learning interests, inducing them to engage in learning, taking into consideration their different cognitive abilities and learning methods [7].

Interactive environments can provide more sophisticated and controllable learning practices, exploring new teaching approaches involving physical movement that allow the child to move around less constrained than when confined to a chair. Thus, in contrast to traditional methods, interactive environments support multimodal and bodily experiences being therapeutically relevant as the content of the interaction addressing the dynamics of social interactions [8].

For example, students can manipulate and visualize difficult math concepts, using virtual 'concrete' materials or internet math games that are very engaging to transfer their learning to abstract concepts relating to fractions. Exploring various features of IWB's technology and gaining in confidence, teachers transform their IWB teaching in an evolutionary process, scaffolding their pedagogy to e- teaching, allowing them teach multi-sensory, multifaceted style of lessons, where they manage a digital convergence from a wide range of sources and devices when reflecting with a class group [9].

Concerning the field of virtual interfaces, the main purpose is to design different courses for children with different disabilities, because they provide real-time feedbacks, focus on easy operate and easy use and produce fun in 
learning. In addition, assistive technology is a helpful method for teachers to explain difficult concepts, providing access to a huge range of examples and resources and facilitating pupils to engage in learning aspects easily [10].

\section{IWBS' IMPACT ON STUDENTS WITH LEARNING DisABILITIES}

It is commonplace that in order to include students with disabilities into the mainstream classroom it is better to provide students of all abilities with an interactive and engaging way to learn information, integrating visual, auditory, touch and movement into the learning process [4].

Hence, teachers are able to monitor student understanding on learning aspects and enable multiple pedagogical approaches, keeping a close eye on their progress before they fall behind. According to the research, it is argued that viewing the IWB as a teaching tool, it does provide added value, enabling the teachers to actually feel the difference it makes to their teaching [11].

The implementation of an IWB in an inclusive classroom could benefit all students and specifically those with special needs increasing their participation due to the interactive nature of the technology or deepen their conceptual understanding by linking visual imagery to information that is difficult to understand when presented solely by text. It is noted that students were more willing to attempt communication with the teacher and peers like being involved in an activity, using their multiple senses [12].

In a qualitative study on the use of the IWB to enhance literacy in children with learning disabilities the researchers used a Technology Integration Model of six phases, as a framework for implementing universal design principles. Results indicated the motivation of children's expression, the ability to explore different levels of multimedia and the visualization of a better mental image than the traditional learning method [13].

Many teachers have found that shared reading and listening of interactive Big Books, being presented and manipulated using the electronic features of the IWB, benefited children and resulted in effective learning even for those with short attention spans. These interactions with and reflections on the writing skills are in line with the UK's Primary National Strategy that provides a framework of teaching objectives based on the belief that the "most successful teaching" is where "interactive pupils" contributions are encouraged, expected and extended" [14].

IWBs offer enormous potential in generating a high degree of interactivity and collaboration among students, between students and curriculum and between students and teacher. Their digital features can be accessed and used in different modes to meet four research-based principles of teaching students with disabilities. 1. Instruction designed around authentic tasks through active classroom technology. 2. Engagement to cognitive strategies that foster either lower or higher ordered skills. 3. Socially mediated learning in which disabled and non- disabled students can make their thinking visible to one another. 4 . Engagement in constructive conversations through visual, audio and kinesthetic reactions [6].

\section{IWBS' IMPACT ON STUDENTS WITH COMPLEX AND MODERATE LEARNING DISABILITIES}

In a study presented by Yakubova Gulnoza and TaberDoughty Teresa, it is illustrated how students with moderate intellectual disability could learn to independently use technology, watching video modeling clips and integrating IWB technology as a self-operated learning device. The researchers argued that students improved independent learning after receiving video modeling instruction via self operating an IWB [15].

While most of the resources that an IWB allows teachers to include within their lessons like CDs, DVDs, video animation, interactive games and internet can be accessed without an IWB, the IWB increase student attention and understanding and improve their behavior in the classroom. Thus, in order to meet visual and conceptual clarity, alternative and augmentative communication, teaching resources and learning materials should be realistically representational [16].

Teachers comment that the IWB's added value generates student learning interest and active engagement in the classroom. Researchers argue that the most important characteristic of IWB is the characteristic of interactivity which relates with the ability to provide both explicit instruction and immediate student feedback [17].

At the conference held for the RA4AL position paper among others, there were presented the following areas of competence needed by teachers to raise the achievements for all learners: effective teaching approaches supporting all learners and meeting a diverse range of needs. It has been recommended as critical in raising achievements for all learners, that teachers must be active agents of the effective strategies (for example team teaching and peer assisted learning) to ensure learning and full participation of all learners [18].

Researchers and educators conclude that several different learning styles are accommodated when learning is delivered with an IWB, fostering teaching and learning even further. Allowing the use of multiple senses, through the features of an IWB, students are driven to increased levels of learning engagement and educators promote their classroom control [5].

Recent developments in the way digital information can be accessed through IWB's features are based on standards that meet disabled students' diverse learning needs, promoting a high degree of interactivity in the classroom. IWB's multimedia and multi sensory capacity are critical factors in facilitating learning for students with moderate learning disabilities, because using visual images result in better understanding, improved attention and behavior [6].

\section{IWBS' IMPACT ON STUDENTS WITH AUTISM SPECTRUM DISORDERS}

In a research study conducted by the University of Wollongong concerning the learning of students with Autism Spectrum Disorders (ASD) in a frame of digital technologies, IWB is viewed as a teaching and learning tool. This study presented the IWB as a tool to enhance teachers' pedagogical goals and as a tool to support specific needs of the students with ASD, such as visual engagement, imagination, self-regulation and social interaction [19].

In another research conducted to examine the effective implementation of a multi-component IWB intervention 
for two students with autism, it is indicated that they learned how to perform novel tasks by self-operating an IWB and improved independent task performance by selfmonitoring it [15].

Moreover, while observing the behaviors of children with ASD, during and after Electronic Screen Media interactions, researchers found interesting results regarding procedural knowledge concerning imitation of sounds, words and actions, increased attention to the screen and reduced response to environmental distractions [20].

IWB's valued feature allows teacher to enhance different learning styles combining visual, tactile, kinesthetic, and auditory inputs that engage better students with ASD. Its visual clarity, visual representation and interactive potential features can support ASD students' attention to filter out stimuli unrelated to a given communication [16].

Interactive environments, in contrast to traditional approaches can provide bodily and multi-modal interactions to children with autism whose imaginative skills do not allow creating different worlds but prefer the concrete and the visible. Thus, for children with autism such environments provide the link to experiences addressing different aspects of the world, dynamically changed and presented differently [8].

Working on the board in groups helps students with ASD to develop gross and fine motor skills and teach them to wait, take turns, hold position and maintain body space. However the researchers believe that only if teachers use IWBs' tools effectively will manage to increase learning outcomes for students with disabilities [17].

It is needed further research on pedagogical approaches and effective strategies to support the management of heterogeneous groups, like children with autism, in shaping the practice where the voice of the learner is the key to inclusion and personalization. Quality in Inclusive Education allows learners to use different styles of learning and assessment to provide opportunities and raise achievement of all learners. It is stressed that the idea that learners from certain groups are low achievers should be replaced by a quality education for all [18].

Grant Shannon and Sally Jo Cunningham in their study investigated the potential of a software-based play activity to support greater physical ranges of movement than is possible on a pc. The learning experience through the use of 'untethered' interfaces, for children with ASD, is developmentally more appropriate. However, comparing the IWB's placement with its effective usage they uncovered negative aspects of its pedagogical use due to its physical installation [1].

Beth A. Mineo, William Ziegler, Susan Gill and Donna Salkin (2008) investigated the engagement potential of Electronic Screen Media (ESM) and measured gaze duration and vocalization among students with Autism Spectrum Disorders. The results reveal differential engagement of ESM alternatives and conclude that generalization of new skills is related to the focus on the instructional value of the scenarios, despite students' utter fascination while using new technologies [21].

\section{IWBS' IMPACT ON DEAF, BLIND AND PHYSICALLY IMPAIRED STUDENTS}

Drawing on the synthesis of the key issues for the Raising Achievement for All Learners (RA4AL) project, among others, the following aspects have been presented:
Personalization through listening to learners to shape educational policy and practice in a more holistic way and pedagogical approaches that benefit all learners [18].

In accordance with these factors teachers construct IWB multisensory learning materials through visual and kinesthetic content that help students with hearing impairments, deafness, mental retardation, orthopedic Impairment, traumatic brain injury or any other condition that define a student with a disability scaffold their own personal knowledge [6].

The use of an Interactive White Board as a communication tool for students with vision disabilities have shown that blind students can be benefited from this approach based on a virtual learning environment using screen readers and interacting with educational resources that had previously been excluded from. In a study conducted by André P. Freire, Flávia Linhalis, Sandro L. Bianchini, Renata P.M. Fortes and Maria da Graça C. Pimentel it is presented an approach on the inclusive features of IWB systems that provide mediation for blind students and enables them to interact directly with textual descriptions [22].

Visually impaired students, whose visual capacity is restricted, benefit from the large size of the IWB screen, its zoom feature that magnifies whatever is presented on the screen, changing backgrounds or text colors, recording instructions for lesson play back and printing class notes to a Braille translator. Thus, learning materials presented through IWBs' multimedia features create stronger memory links and improve students' understanding. The balance, between technical and pedagogical interactivity of IWB potential, lies in the process where students with disabilities manage to keep up with their non disabled peers, who, in turn develop a better view about disability [6].

Teacher and student class discussions can be extended beyond classroom in due to distance learning configuration of the IWB's capabilities and can benefit students that are confined to a bed and are unable to attend school. In addition, students are able to contribute their comments by writing back to the IWB through their computer [6].

Technology developments, including interactive electronic whiteboard, are intended to use a more natural and spontaneous way to fulfill students' multimodal interaction and foster their engagement, attentiveness, participation and learning. Interactive whiteboards may support effectively children with disabilities such as communication senses' problems, limb paralysis, infantile paralysis, partial mental retardation and others that demand an interface interaction, operated by hand gestures, facial expression, body language and speech [23].

\section{IWBS' IMPACT ON ADHD STUDENTS}

The visual, audio and tactile ways in which IWBs present information, where color and movement are prominent, motivate attention and facilitate the learning process. IWBs aid students' concentration and have an impact on preferred approaches to learning such as imagination, demonstration and metacognition [24].

Attention, satisfaction, performance and attitude are major items of students' effective learning through IWB technology, according to Y.K. Türel's research, that refer to student's perceptions towards the IWB use in the classroom in relation to learning and motivation[25]. 
Syh-Jong Jang and Meng-Fang Tsai (2012) conducted a survey examining the reasons for using Interactive Whiteboards to enhance both teaching and learning efficiency and showed that IWBs not only allow teachers get students' attention and help them concentrate on learning but increase flexible interactions between teachers and students, too [26].

Children with attention deficit disorders improve their learning skills stimulating different senses through multimodal interfaces of IWB technology consisted by multiplicity and modality where sight, hearing, touch, smell and gesture recognition are being involved [23].

\section{CONCLUSIONS}

Classroom observations on the progress of young children with difficulties in their writing skills and older pupils with special educational needs show high motivation of their skills and knowledge implementing features of the IWB, like tapping and dragging, especially when they use it alone or in small groups. The more the IWB embeds in teachers' pedagogy, the more interactive becomes their teaching, adjusting it to an inclusive and cooperative practice [27].

Among the children of a classroom those with learning difficulties in numeracy and literacy appeared to improve their outcomes having the most benefit. Similar improvement in their assessment results showed the kinesthetic and visual learners, which may have been benefited by the hands on nature of problem solving and the visual displays indicating attention and confidence in learning. [28].

IWB provides a multi literacy teaching and learning environment where teachers reflect with a multi sensory, multi faceted presentation style and students experience an e-teaching approach that facilitates group activities, group sharing, tactile interactions into the process of gaining class attention [9].

IWB use relates to the teacher's and students' perceptions of how it can be used as being critical agents in mediating the software to promote quality interactions and enhance interactivity in the process of changing their pedagogic practices to understand and unpack the complexities of their students [29].

The effectiveness of IWB has been proved by demonstrating teaching efficiency, versatility, multimodal presentation and interactivity transformed into a longer degree of engagement and participation, motivation, pace and flow for the less able students who prefer to drag words and images as "hands-on' interactions. Teachers use IWB technology maintaining learner's attention labeling, highlighting and coloring features of the content in a continued high level of participatory pedagogy [30].

There is solid ground based on the results of studies to believe that IWBs are not only effective for instruction in general education classrooms, but also effective in special education settings making specific recommendations of the possible improvements that could be made utilizing IWB, for students with disabilities. Thus, students with severe attention difficulties were helped to maintain attention to tasks and those with fine motor difficulties worked on coordination [2].

IWBs' technology based instruction generated a high degree of interactions that created a new pedagogical environment among students, between students and curriculum, and between students and teacher creating alter- native learning pathways, through active classroom, for all students - particularly those with disabilities [6].

After close observation and analysis it is showed that both technical and pedagogic interactivity can motivate learning skills but it is only the features of pedagogic interactivity that stimulate in depth the characteristics of higher-order learning and provide greater learner autonomy [31].

The key to an effective IWB-based pedagogy is seeing the board as a multimodal hub to orchestrating a synergistic environment for the construction of knowledge (e.g. open problem-solving, creating product, questioning and critical applications of concepts) [32].

IWBs can initiate and facilitate learning and metacognition process effectively through visual and verbal-social features of the built-in software and hardware technology, which is being presented through color and movement, and being viewed by the majority of students positively, for many different reasons such as the visual display of information, the use of games, the concentration and the use of the board by the students themselves [33].

Furthermore, IWBs enable teachers to perform a speedy, smooth presentation of innovative style of multimodal information and produce a very lively, interactive lesson, transforming teaching effectively through extended teacher-pupil dialogue [34].

The advantage to accommodate different learning styles through the IWB enables teachers to support the development of resources, improves presentation, motivates students to interact with learning aspects, demonstrates ICT skills and engages pedagogy in the classroom [11].

Interactive technology framework addressed through IWBs enable intelligent techniques that are applied through Artificial Intelligence Techniques to solve problems in the area of special education aiming to the freedom of action of the user [35].

\section{REFERENCES}

[1] Shannon, Grant and Cunningham, Sally Jo: Impact of classroom design on interactive whiteboard use in a special needs classroom, Proceedings of the 10th International Conference NZ Chapter of the ACM's Special Interest Group on Human-Computer Interaction, 1-4, 2009

[2] Bethany Stiefel, Interactive White Board Use in the SelfContained Special Education Classroom, 2011

[3] A. Czyzewski and B. Kostek, Intelligent Multimedia Solutions Supporting Special Education Needs, 19th International Symposium, Warsaw, Poland, pp 1-15, 2011

[4] Accessibility Partners, LLC: Interactive Whiteboard Technology: Strategies for Special Needs Students, 2011

[5] SMART Technologies White Paper, Interactive Whiteboards and Learning, Improving student learning outcomes and streamlining lesson planning, 2006

[6] Omar Lopez, White Paper, Lighting the Flame of Learning for Students with Disabilities Through the Use of Interactive Whiteboard Technology, 2006

[7] C.-Y. Lin et al., Assessment of the Application of Wii Remote for the Design of Interactive Teaching Materials, Information and Management Engineering, Volume 235, pp 483-49, 2011 http://dx.doi.org/10.1007/978-3-642-24022-5_77

[8] Kerstin Dautenhahn, Design Issues on Interactive Environments for Children with Autism, Proceedings International Conference on Disability, Virtual Reality and Associated Technologies, p.153-161, 2000

[9] Peter Kent: Smart boards: Interactive Whiteboards in Classrooms Embedding Learning Technologies Module 13, 15th International 
Conference of the Society of Information Technology and Teacher Education, Atlanta USA, 2004

[10] C.-Y. Lin et al., Application of Interactive Interface Design on Rehabilitation for Children with Cerebral Palsy, Future Communication, Computing, Control and Management, Lecture Notes in Electrical Engineering Volume 142, 2012, pp 361-367, 2012

[11] Paul Kelley, Guy Underwood, Franc Potter, Jane Hunter \& Sue Beveridge : VIEWPOINTS, Learning, Media and Technology, 32:3, 333-347, 2007 http://dx.doi.org/10.1080/1743988070151 1164

[12] Kristin A. Anderson, Increasing Participation of Students with Special Needs with an Interactive Whiteboard, A Grant Proposal Project Report Submitted in Partial Fulfillment of the Requirements for the Master of Science Degree in Education, University of Wisconsin-Stout, 2008

[13] Kelly Huck, Dough Schmitz, Universal Design for Learning In Practice, Report on the use of the SMART Board Interactive Whiteboard to enhance Literacy in Children with Learning Disabilities

[14] Martin, S., Interactive whiteboards and talking books: a new approach to teaching children to write?. Literacy, 41: 26-34, 2007 http://dx.doi.org/10.1111/j.1467-9345.2007.00449.x

[15] Yakubova Gulnoza, Taber-Doughty Teresa, Brief Report: Learning Via the Electronic Interactive Whiteboard for Two Students with Autism and a Student with Moderate Intellectual Disability, Journal of Autism \& Developmental Disorders, Vol. 43 Issue 6, p1465, 2013

[16] Jo Egerton, Jan Cook, Cheryl Stambolis, Developing a Model of Pedagogical Best Practice in the Use of Interactive Whiteboards for Children with Autism and Complex Learning Disabilities: Implications for Initial Teacher Training, Training and Development Agency for Schools, 2009

[17] David H. Allsopp, Karen Colucci, Elizabeth Doone, Luis Perez, Ezzard Bryant, Jr., and Tina N. Holhfeld Interactive Whiteboard Technology for Students with Disabilities: A Year Long Exploratory Study, JSET volume 27 number 4, pages 1-15, 2012

[18] European Agency for Development in Special Needs Education, Raising Achievement for all Learners, Quality in Inclusive Education, 2012

[19] Verenikina, I., Tanner, K., Dixon, R. M. \& de Graaf, E. Interactive Whiteboards as a Tool for Teaching Students with Autism Spectrum Disorders. In S. Katherine. Howard (Eds.), Making a Difference, Conference Papers of AARE Melbourne: AARE, 2010

[20] Howard C. Shane, Patti Ducoff Albert, Electronic Screen Media for Persons with Autism Spectrum Disorders: Results of a Survey, Journal of Autism and Developmental Disorders Volume 38, Issue 8, pp 1499-1508, 2008

[21] Beth A. Mineo, William Ziegler, Susan Gill, Donna Salkin, Engagement with Electronic Screen Media Among Students with Autism Spectrum Disorders, Volume 39, Number 1, page 172, 2009

[22] André P. Freire, et al., Revealing the whiteboard to blind students: An inclusive approach to provide mediation in synchronous elearning activities, Computers \& Education, Volume 54, Issue 4, Pages 866-876, 2010 http://dx.doi.org/10.1016/j.compedu. 2009.09.016

[23] Andrzej Czyzewski, Bozena Kostek, Intelligent Multimedia Solutions Supporting Special Education Needs, Foundations of Intelligent Systems Lecture Notes in Computer Science Volume 6804, pp 1-15, 2011

[24] Wall, K., Higgins, S. and Smith, H., 'The visual helps me understand the complicated things': pupil views of teaching and learning with interactive whiteboards. British Journal of Educational Technology, 36: 851-867, 2005 http://dx.doi.org/10.1111/j.1467$\underline{\text { 8535.2005.00508.x }}$

[25] Yalın Kılıç Türel, An interactive whiteboard student survey: Development, validity and reliability, Computers \& Education, Volume 57, Issue 4, Pages 2441-2450, 2011

[26] Syh-Jong Jang and Meng-Fang Tsai Reasons for Using or Not Using Interactive Whiteboards: Perspectives of Taiwanese Elementary Mathematics and Science Teachers Australasian Journal of Educational Technology, v28 n8 p1451-1465, 2012
[27] Cathy Lewin, Bridget Somekh, Stephen Steadman, Embedding interactive whiteboards in teaching and learning: The process of change in pedagogic practice, Education and Information Technologies, Volume 13, Issue 4, pp 291-303, 2008 http://dx.doi.org/10.1007/s10639-008-9070-z

[28] Karen White, Interactive Whiteboard Trial, South Western Sydney Region: A Report, 2007

[29] Victoria Armstrong, et al., Collaborative research methodology for investigating teaching and learning: the use of interactive whiteboard technology, Educational Review, 57:4, 457-469, 2005 http://dx.doi.org/10.1080/00131910500279551

[30] Steve Kennewell \& Gary Beauchamp, The features of interactive whiteboards and their influence on learning, Learning, Media and Technology, 32:3, 227-241, 2007 http://dx.doi.org/10.1080/17439880701511073

[31] Kennewell, S., Tanner, H., Jones, S. and Beauchamp, G., Analysing the use of interactive technology to implement interactive teaching. Journal of Computer Assisted Learning, 24: 61-73, 2008 http://dx.doi.org/10.1111/j.1365-2729.2007.00244.x

[32] Gary Beauchamp, Steve Kennewell, Transition in pedagogical orchestration using the interactive whiteboard, Education and Information Technologies, Volume 18, Issue 2, pp 179-191, 2013 http://dx.doi.org/10.1007/s10639-012-9230-z

[33] Wall, K., Higgins, S. and Smith, H., 'The visual helps me understand the complicated things': pupil views of teaching and learning with interactive whiteboards. British Journal of Educational Technology, 36: 851-867, 2005 http://dx.doi.org/10.1111/j.14678535.2005.00508.x

[34] Julia Gillen, Judith Kleine Staarman , Karen Littleton, Neil Mercer \& Alison Twiner, A 'learning revolution'? Investigating pedagogic practice around interactive whiteboards in British primary classrooms, Learning, Media and Technology, 32:3, 243256, 2007 http://dx.doi.org/10.1080/17439880701511099

[35] Athanasios S. Drigas, Rodi-Eleni Ioannidou, A Review on Artificial Intelligence in Special Education, Information Systems, Elearning, and Knowledge Management Research Communications in Computer and Information Science Volume 278, pp 385-391, 2013 http://dx.doi.org/10.1007/978-3-642-35879-1_46

\section{AUTHORS}

Athanasios Drigas is a Senior Researcher at IIT, N.C.S.R. Demokritos. He is the Coordinator of Telecoms Lab and founder of Net Media Lab since 1996. From 1985 to 1999 he was the Operational manager of the Greek Academic network. He has been the Coordinator of Several International Projects, in the fields of ICTs, and eservices (e-learning, e-psychology, e-government, einclusion, e-culture etc). He has published more than 240 articles, 7 books, 25 educational CD-ROMs and several patents. He has been a member of several International committees for the design and coordination of Network and ICT activities and of international conferences and journals. He has also received several distinctions for his scientific work (articles, projects, patents). (e-mail: dr@iit.demokritos.gr).

George Papanastasiou is a Special Education Teacher at a public primary school in Athens. Among various research projects, in the framework of the project "Further training of educators in the use and application of ICTs in the teaching practice" under the Education and Life-Long Learning Operational Programme, Ministry of Education and Religious Affairs, he has co-authored Volume A "Theoretical Framework: The Interactive Whiteboard in the school classroom: Pedagogical Approaches - Teaching Applications" and Volume B "Educational Scenarios for the Use of the Interactive Whiteboard". (e-mail gpapanasta@gmail.com).

Submitted 04 July 2014. Published as resubmitted by the authors 25 October 2014. 